\title{
Punishment models of addictive behavior
}

\author{
Louk JMJ Vanderschuren, A Maryse Minnaard, \\ Johanna AS Smeets and Heidi MB Lesscher
}

\begin{abstract}
Substance addiction is a chronic relapsing brain disorder, characterized by loss of control over substance use. In recent years, there has been a lively interest in animal models of loss of control over substance use, using punishment paradigms. We provide an overview of punishment models of addiction, that use quinine, histamine, lithium chloride and footshocks as aversive stimuli, and we discuss the merits and drawbacks of these approaches. Importantly, many studies have demonstrated that under certain conditions, animals are willing to endure punishment during the pursuit of substances of abuse, which captures an essential component of addictive behavior. We conclude that punishment models of addiction represent a valuable contribution to the study of addiction.
\end{abstract}

\author{
Address \\ Dept. of Animals in Science and Society, Division of Behavioural \\ Neuroscience, Faculty of Veterinary Medicine, Utrecht University, \\ Utrecht, The Netherlands \\ Corresponding author: Vanderschuren, Louk JMJ \\ (I.j.m.j.vanderschuren@uu.nl) \\ Current Opinion in Behavioral Sciences 2017, 13:77-84 \\ This review comes from a themed issue on Addiction \\ Edited by Scott Edwards and Karen D Ersche \\ For a complete overview see the Issue and the Editorial \\ Available online 18th November 2016 \\ http://dx.doi.org/10.1016/j.cobeha.2016.10.007 \\ 2352-1546/C 2016 Elsevier Ltd. All rights reserved.
}

\section{Introduction}

Addiction to substances of abuse remains an enormous global health problem. It has been estimated that 76 million people worldwide are addicted to alcohol [1], 29 million people are addicted to illicit drugs, such as opiates, psychostimulants and cannabis [2] and 1.1 billion people smoke tobacco [3], a substantial proportion of which can be considered addicted. Alongside the suffering inflicted by the addictive behavior itself, substance addiction dramatically increases the risk for a wide range of communicable and non-communicable diseases, including lethal conditions such as cardiovascular problems, liver failure and cancer. Indeed, substance addiction is considered to be one of the leading causes of premature death worldwide [1-3]. Remarkably, only 1 in 6 addicts are estimated to be in treatment [2], and the treatment options available are modest in terms of number and efficacy $\left[4^{\bullet}, 5,6\right]$. In order to develop improved treatment strategies for addiction, we think that a profound understanding of the neural underpinnings of addictive behavior is essential.

For more than half a century, animal models have been used to investigate the behavioral and neural mechanisms of addiction. The positive affective, reinforcing properties of substances of abuse have been widely studied using place conditioning $[7,8]$ and intracranial self-stimulation methods [9,10]. Arguably the greatest progress in understanding addictive behavior using animal models has come from oral and intravenous self-administration studies, that derive considerable validity by virtue of the fact that they employ voluntary, active intake of drugs of abuse [11,12]. Moreover, self-administration setups have shown to be a versatile method to investigate addictive behavior, in the sense that variants of this paradigm have been developed to study the incentive motivational properties of substances of abuse [13,14], the role of drug-associated cues in addictive behavior [15,16], and relapse to extinguished drug seeking [17,18].

The most recent development in animal models of addictive behavior constitutes models that explicitly study loss of control over substance seeking and taking. Inspired by the realization that the majority of the diagnostic criteria for addiction in DSM-IV [19] and DSM5 [20] comprise behaviors that signify a lack of control over substance use, researchers have started to develop models that capture these compulsive aspects of addictive behavior. Many of these studies have focused on the DSM criterion of continued substance use despite negative consequences, and have operationalized this as resistance to punishment $\left[21^{\bullet}, 22\right]$. In the paradigms that have been used, the pursuit of substances was associated with aversive events or circumstances, and the willingness of animals with a certain predisposition or substance taking history to endure this adversity when access to substance is at stake was assessed. In this overview, we will present punishment models of compulsive substance use, highlight their merits and drawbacks, and discuss challenges for future research.

\section{Punishment models of addictive behavior Quinine}

Perhaps the first use of a punishment setup in the context of addiction research is the work of Wolffgramm and 
colleagues, who studied alcohol addiction-like behavior in rats [23,24]. The manipulation they used is to render the taste of orally ingested alcohol aversive using the bitter tastant quinine. They observed that the efficacy of quinine to reduce alcohol intake substantially declined after prolonged periods of alcohol drinking, interspaced with periods of forced abstinence. This reduced sensitivity of alcohol intake to quinine was accompanied by a loss of sensitivity to other factors that influence alcohol drinking, such as social rank and social isolation. Comparable findings were later reported for other substances of abuse, including opiates and psychostimulants [24-26]. The finding of reduced sensitivity of alcohol drinking to quinine after prolonged alcohol intake has subsequently been replicated in rats and mice $\left[27,28^{\bullet \bullet}, 29,30,31^{\bullet}, 32,33\right]$. In rats, this relative insensitivity to quinine was observed after prolonged exposure to an intermittent (rather than continuous) pattern of alcohol access $\left[27,28^{\bullet \bullet}, 32\right]$, and sometimes in high alcohol consuming rats only [30]. In these experiments in rats, quinine-containing alcohol was the only source of alcohol during the test. Interestingly, experiments in mice have shown comparable findings, for example, willingness to drink bitter, quinine-containing alcohol if water is the only alternative fluid [29,33]. Moreover, after two months of voluntary alcohol drinking, mice continued to drink quinine-containing alcohol even if non-adulterated alcohol was simultaneously available [29]. Importantly, in these latter experiments, regardless of experience with alcohol drinking, all mice avoided quinine-containing water, indicating that the persistent intake of quinine-containing alcohol was not the result of altered taste perception [29].

\section{Lithium chloride and histamine}

In order to associate substance intake with interoceptive malaise, post-ingestion treatment with lithium chloride has been used. This approach is widely used to evoke conditioned taste aversion, and to assess the ability of animals to use a representation of the value of a reinforcer to direct operant behavior [34]. The first of these studies showed that taste aversion conditioning with lithium chloride profoundly reduced the oral intake of alcohol and cocaine solutions, yet did not alter responding in extinction for alcohol and cocaine $[35,36]$. These findings suggest that acts distal to substance use (i.e. attempts to obtain the substance) are less sensitive to punishment than the actual substance intake, as long as the taste memory trace provides explicit feedback of the degraded value of alcohol and cocaine after its association with interoceptive malaise. Recently, also the sensitivity of intravenous cocaine self-administration in rats to lithium chloride-induced malaise was investigated $\left[37^{\circ}\right]$. The findings were comparable to those described above $[35,36]$, inasmuch as that cocaine taking was sensitive to devaluation, whereas responding for a cocaine-associated cue was not. Importantly, the sensitivity to lithium chloride was lost in animals with a history of lengthy cocaine self-administration sessions $\left[37^{\circ}\right]$. Interoceptive aversion has also been employed using intravenous histamine as a punisher in rats and non-human primates [3840]. When histamine was added to the solution for intravenous cocaine self-administration, this reduced responding for cocaine, while at the same time increasing responding for concurrently available food or unadulterated cocaine $[39,40]$. Importantly, the aversive effects of histamine, by intravenous infusion, are direct (as compared to the delayed aversive effects of lithium chloride treatment after self-administration). Indeed, when infusion of histamine was delayed (i.e. for seconds to minutes after cocaine infusion), its ability to reduce responding for cocaine was found to decline [40].

\section{Footshock}

The most widely applied punisher in substance selfadministration studies is mild electric shock. Originating from Jenkins' obstruction box studies [41], initial studies in primates showed that response-contingent shocks reduced cocaine self-administration, whereby shocks of higher intensity were more effective, and delayed shocks less effective $[42,43]$. In the last decade, this setup has been widely used in rats [44-48]. In an influential study, Deroche-Gamonet $e t$ al. described that responsecontingent footshocks suppressed responding for cocaine in rats [45], but that in a subgroup of rats, the sensitivity to footshock profoundly declined after a lengthy cocaine taking history. This latter subgroup of animals was also characterized by high levels of cocaine-induced reinstatement of responding after extinction. Moreover, these rats showed other signs of addictive behavior as well, such as high motivation for cocaine under a progressive ratio of reinforcement and persistence of non-reinforced responding, albeit that these different addiction-like behaviors did not emerge simultaneously [45]. Subsequent experiments showed that this addiction-like behavior could be predicted on the basis of impulsive behavior (i.e. premature responses in the 5-choice serial reaction time task), irregular patterns of cocaine self-administration and a high preference for a novel environment, but not noveltyinduced hyperlocomotion [46-48].

In the studies described above, every substance taking episode was punished, and in the studies by DerocheGamonet, Belin and colleagues [45-48], the response preceding the one that lead to cocaine infusion was punished as well (i.e., the fourth and fifth response under a fixed-ratio 5 schedule of reinforcement). Since in humans, not every instance of substance taking has inevitable and direct negative consequences, other studies have used somewhat different punishment procedures. For example, footshock punishment was made probabilistic, whereby one in eight responses was punished with a footshock, and one in three responses was reinforced with alcohol $\left[28^{\bullet \bullet}\right]$. Thus, even though alcohol taking was punished, delivery of alcohol was more frequent than 
punishment. With this approach, a subgroup of rats was shown to become insensitive to footshock punishment. Other studies have moved punishment of responding forward in time, for example, to the acts directed at obtaining cocaine. To achieve this, Pelloux, Everitt and colleagues $\left[49,50,51^{\circ}\right]$ have used a seeking-taking chain schedule of reinforcement, in which rats were trained to respond on one lever ('seeking lever') in order to gain access to a second, 'taking' lever, responding on which produced an intravenous infusion of cocaine. After training, half of the seeking episodes did not lead to presentation of the taking lever, but was punished with a mild electric footshock. Whereas the majority of animals showed profoundly reduced cocaine seeking when the punishment contingency was introduced, a subgroup of animals did not, albeit after a prolonged cocaine taking history [49]. Comparable findings were reported by others, in setups in which seeking, when punished, did [52], or did not allow for subsequent cocaine taking [53 $3^{\bullet \bullet}$. Further analysis of this behavior showed that insensitivity to punishment was the result of excessive drug exposure rather than experiencing a large number of cocaine-cue associations [50]. In a subsequent study, punishment of seeking (i.e. footshock after fulfilling the response requirement on the seeking lever) or taking (i.e. footshock after responding on the taking lever) was compared. The data showed that rats were more willing to endure punished taking than seeking $\left[51^{\circ}\right]$, suggesting that punishment of distal substance seeking acts is more effective in reducing addictive behavior than punishment of the actual use of the substance. Importantly, the availability of response-contingent sucrose increased the effectiveness of punishment to reduce cocaine seeking. Threat of adversity has also been used in the context of addictive behavior, as an alternative to immediate and inevitable punishment. To this aim, auditory cues previously associated with mild electric footshocks were used to influence cocaine seeking [54-56]. These experiments revealed that presentation of a footshock-associated cue suppressed cocaine seeking, but after limited drug taking experience only. Thus, after an extended cocaine selfadministration history, the effectiveness of the footshockassociated cue to alter cocaine seeking profoundly declined $[54,56]$. A different threat model has been used in studies on eating disorders, in which rats or mice have to enter an aversive, brightly lit environment in order to get access to a preferred food $[57,58]$. This approach has as yet not been used in the context of self-administration of substances of abuse.

Punishment of cocaine and heroin self-administration has recently also been performed in studies in which Jenkins' obstruction box [41] was revisited. Thus, in these experiments, rats had to cross an electrified grid to reach the lever, pressing which produced an infusion of the drug [59-62]. For each individual animal, the shock intensity that completely suppressed responding for the drug was determined, after which reinstatement of responding for drug-associated cues was assessed. Interestingly, reinstatement of responding for cocaine was only observed in about half of the rats, whereas in the case of heroin, all rats showed cue-induced reinstatement of responding [60,61]. Last, footshock-induced punishment of alcohol and methamphetamine self-administration has also been used as a method to make rats cease responding for the respective substance, in order to assess context- [63] or cue-induced reinstatement of responding [64].

\section{Punishment models of addictive behavior: merits and drawbacks}

The studies discussed above describe approaches aimed at emulating persistent substance use despite negative consequences. Clearly, these have substantially moved the preclinical addiction field forward by demonstrating that aversive stimuli of different modalities, including gustatory (quinine), interoceptive (lithium chloride, histamine) and tactile (footshock) ones, can inhibit behavior directed at substances of abuse. More importantly, a substantial proportion of these studies also reports that animals with a certain predisposition and/or self-administration history display reduced sensitivity to aversive interference $\left[23,24,27,28^{\bullet \bullet}, 29,30,35,36,37^{\bullet}, 45-50,51^{\bullet}, 52\right.$, $\left.53^{\bullet}, 54,56\right]$, which resembles the aberrant, unflagging pursuit of substances of abuse in human addicts $[19,20]$. These contemporary setups of addiction-like behavior hold great promise to increase our understanding of the neural and behavioral structure of substance use disorders. Indeed, recent years have seen explicit progress in the study of the neural underpinnings of addiction using punishment models $\left[28^{\bullet \bullet}, 31^{\bullet}, 52,53^{\bullet \bullet}, 65-71\right]$.

\section{Quinine and histamine}

An issue that needs to be considered with care is which aspect of substance use is being punished in these models. Indeed, gustatory, interoceptive and tactile punishers have all been scrutinized for their validity to study human addictive behavior. The bitter taste of quinine is a gustatory punisher, that is immediately apparent following ingestion of alcohol (as well as other substances of abuse in oral consumption experiments [24-26]). As such, it is an immediate punisher of alcohol drinking, and the sensation of its bad taste actually precedes the perception of the subjective effects of alcohol. It is useful to realize that taste is an important aspect of alcohol ingestion, and that one of the behavioral characteristics of alcohol addiction is the ingestion of unpalatable (cheap, but with high alcohol content) liquors, in order to maximize alcohol intake at minimal financial cost. In extreme cases, alcohol addicts even ingest unsavory alcohol-containing products not intended for human consumption, such as mouthwash and aftershave [72,73], whereby taste has obviously become less important than alcohol content. The willingness of animals to endure the bitter taste of quinine, if this is the only way of obtaining alcohol 
$\left[23,24,28^{\bullet \bullet}, 29,30\right]$, reflects the reduced importance of taste in alcohol addiction, which is perhaps even better exemplified by the continued ingestion of quinine-containing alcohol when non-adulterated alcohol is simultaneously available [29]. Comparable to quinine in terms of its immediacy is the interoceptive discomfort induced by intravenous histamine, which has been shown to be an efficient punisher of cocaine self-administration [3840]. Resistance to histamine punishment has so far not been demonstrated in an animal study, although this may be a matter of histamine dose and/or cocaine selfadministration experience rather than histamine being a stronger punisher than quinine, lithium chloride or footshock.

\section{Lithium chloride}

Somewhat different to quinine and histamine, the aversive effects of lithium chloride-induced malaise emerge with a delay after substance taking. This delay stems both from the slower onset (and probably longer duration) of the lithium chloride-induced interoceptive effects compared to the rapid subjective substance effects, but also from the practical point that lithium is passively administered to the animal after drug exposure [35,36,37 ${ }^{\circ}$. In this regard, lithium chloride may more closely emulate the visceral discomfort that follows substance taking episodes, such as the gastrointestinal pain that alcohol addicts may suffer from, as well as the physical malaise that characterizes an alcohol hangover or cocaine crash. Remarkably, the studies that have employed lithium chloride to punish addictive behavior have found that it only reduces proximal substance taking acts (i.e. drinking alcohol and cocaine solutions, intravenous cocaine self-administration) but not behaviors distal to substance use, such as responding for cocaine or alcohol in extinction (i.e. without immediate gustatory feedback about the degraded reinforcer) and responding for cocaine cues $\left[35,36,37^{\circ}\right]$. This indicates that the effectiveness of punishment declines with increasing temporal distance, consistent with the classic observation that the strength of a learning process declines with the delay between action and outcome [74].

\section{Footshock}

As is clear from the studies discussed here, mild electric shocks are the most widely employed punisher in preclinical addiction research $\left[28^{\bullet \bullet}, 41-50,51^{\bullet}, 52,53^{\bullet \bullet}, 54-64\right]$. This has probably both scientific reasons, as the large number of fear conditioning studies in the literature yields an enormous database of methodological and neural background information, as well as practical reasons. Thus, the intensity, quantity and probability of footshocks can easily be varied, which renders this a very versatile way of interfering with behavior. Comparable to quinine and histamine, footshocks are often used as an immediate punisher of substance use, but the manner in which addictive behavior is punished is likely to be different. That is, the sensation of footshock is immediate, noxious, and brief, and the expectation of footshocks generates a state of conflict and fear. This may emulate the emerging adverse consequences of persistent substance use in humans, in which the user has to weigh the immediate positive experience of substance use against the possible adverse consequences, such as job loss, relationship crisis or disease. Comparable to quinine and lithium chloride, it has also been shown that under certain conditions, animals are willing to endure mild electric footshocks in order to obtain cocaine or alcohol $\left[28^{\bullet \bullet}, 45-50,51^{\bullet}, 52,53^{\bullet \bullet}\right]$. From a naturalistic point of view, the validity of footshocks for human addictive behavior may be less than the other punishers discussed here. Thus, the pursuit or use of substances in humans is typically not followed by noxious, physical punishment, whereas, as discussed above, addicts are confronted with bad taste or interoceptive malaise as a result of their substance use. That said, a recent study in humans has shown that cocaine addicts are less proficient in the avoidance of electric shocks, suggesting that reduced sensitivity to physical punishment does play a role in addictive behavior $\left[75^{\circ}\right]$.

\section{The validity of immediate punishment}

A limitation that is often noted for experimental approaches as discussed here is the immediacy of punishment. Although the timing of its consequences remains largely unclear, substance use in humans is usually not punished immediately and inevitably. Rather, the negative consequences of addictive behavior are often delayed, probabilistic and difficult to trace back to single substance use episodes. In fact, the observation that delayed punishment (compared to immediate punishment) is substantially less effective in interfering with cocaine self-administration [40,43] perhaps illustrates the very nature of addiction, in that substance abuse persists despite negative, but often delayed consequences. In order to use footshock punishment in a way that more closely emulates the human situation where the adverse sequelae of substance use can be rather unpredictable, researchers have therefore also used probabilistic shocks $\left[28^{\bullet}, 49,50,51^{\bullet}, 52\right]$. An alternative approach has used threat of footshock punishment, rather than the shocks themselves [54-56], to model seeking substances in a situation where this entails danger (for example, trying to buy drugs while there is police surveillance on the street). Likewise, these approaches have revealed conditions in which animals endure shock or threat when seeking or taking substances of abuse $\left[28^{\bullet \bullet}, 49,50,51^{\bullet}, 54,56\right]$. One could therefore argue that models using threat of adversity or unpredictable adversity more closely capture the anticipation of adverse consequences at the time of substance use, that probably better reflects the internal conflict that human addicts experience. In any event, understanding the relative timing between substance use and adverse consequences, and how this impacts on use, 
is one of the main challenges in the management of addiction, and this knowledge should be incorporated into the design of animal models of addictive behavior.

\section{Understanding interventions}

The overarching aim of the studies discussed here has been to develop and use animal models to elucidate the neural underpinnings of addictive behavior. Subsequently, these approaches can be used to test the effects neural manipulations on addiction $\left[28^{\bullet \bullet}, 53^{\bullet \bullet}, 67,68\right]$. In addition, they can also help understand the effectiveness of behavioral strategies to influence addictive behavior. For example, the findings that behaviors proximal to substance use are more sensitive to punishment than distal ones if substance intake is punished $\left[35,36,37^{\circ}\right]$ is very informative about the structure of addictive behavior. Thus, even if substance taking has negative consequences, this may not alter their procurement, since the temporal distance between seeking substances and the sensation of punishment after substance intake may be too long [74]. An important study in this regard has been performed by Pelloux and colleagues [ $\left.51^{\circ}\right]$, who reported that punishing distal behaviors (i.e., cocaine seeking) is more effective than punishing cocaine taking, suggesting that interfering with substance use in an early stage of the chain of substance-directed behaviors may yield better results. Also encouraging is the finding in this study $\left[51^{\circ}\right]$ that the availability of an alternative source of reinforcement (i.e., response-contingent sucrose) further reduces cocaine seeking and taking, suggesting that positive (i.e. an alternative source of reinforcement) and negative incentives (i.e. punishment) can have additive beneficial effects on addictive behavior.

\section{Other aspects of addictive behavior}

A limitation of punishment studies discussed here is that they only model part of the addictive behavior in humans. Thus, whereas one can argue that 9 out of 11 diagnostic criteria in DSM5 comprise behaviors representing loss of control over substance use [20], punishment setups emulate only two of those (i.e., recurrent use in situations in which it is physically hazardous; continued use despite knowledge of substance-related problems). Therefore, if one aspires to generate an animal model that captures multiple aspects of addiction, other signs of addictive behavior should be incorporated as well [21 $\left.{ }^{\circ}\right]$. These include high motivation to work for substances (as a model of devoting a great deal of time to procuring, consuming and recovering from use), responding in extinction (to model persistent desire or unsuccessful attempts to restrict use), reinstatement of substance seeking (as a model of craving), choosing substances over natural reinforcers (to model the neglect of alternative, social and professional, sources of reward), and the effects of social isolation and social rank (as a model of continued use despite persistent social problems caused by use and giving up important social activities in favor of use) $\left[18,45,46,76-80,81^{\bullet}, 82,83\right]$. The validity of these models is beyond the scope of this paper, but we do acknowledge the value of these approaches for the study of addictive behavior. On the other hand, we think that employing single-aspect models allows for the investigation of the neurobiological underpinnings of distinct aspects of addiction in isolation. In this regard, it is important to keep in mind that addiction is a multi-faceted disorder, in which different aspects, criteria or behavioral aberrations may play a role, depending on, for example, the substance abused, the history of the individual, or the environmental circumstances. Importantly, neurobiological studies in which different aspects of addictive behavior have been combined have provided evidence that exaggerated motivation, responding in extinction, reinstatement of extinguished responding and resistance to punishment rely on distinct neural mechanisms [84-86].

\section{Conclusion}

The last two decades have seen a remarkable interest in the use of punishment paradigms to model the persistent aspects of substance use disorders. These models have used punishments from different sensory modalities, and methodological variations in these setups allow for the assessment of distinct aspects of loss of control over substance use. Although these punishment setups may arguably still be in development, we expect that their optimization and integration with other models, capturing yet other aspects of addictive behavior such as exaggerated motivation for substances and relapse, will make a valuable contribution to our knowledge about the neural and behavioral structure of addiction. This may ultimately contribute to the development of more effective treatments for this devastating disorder.

\section{Conflicts of interest}

The authors declare that, except for income received from their primary employers, no financial support or compensation has been received from any individual or corporate entity over the past three years for research or professional service and there are no personal financial holdings that could be perceived as constituting a potential conflict of interest.

\section{Acknowledgements}

Supported by ZonMw (the Netherlands Organization for Health Research and Development) Grant 91214093.

\section{References and recommended reading}

Papers of particular interest, published within the period of review, have been highlighted as:

- of special interest

-. of outstanding interest

1. World Health Organization: Global Status Report on Alcohol 2004. 2004.

2. United Nations Office on Drugs and Crime: World Drug Report 2016. 2016. 
3. World Health Organization: WHO Global Report on Trends in Prevalence of Tobacco Smoking. 2015.

4. van den Brink W: Evidence-based pharmacological treatment

- $\quad$ of substance use disorders and pathological gambling. Curr Drug Abuse Rev 2012, 5:3-31.

A comprehensive and thoughtful overview of the available pharmacotherapies for tobacco, alcohol, opiate, cocaine and cannabis addiction and pathological gambling.

5. Potenza MN, Sofuoglu M, Carroll KM, Rounsaville BJ: Neuroscience of behavioral and pharmacological treatments for addictions. Neuron 2011, 69:695-712.

6. Pierce RC, O'Brien CP, Kenny PJ, Vanderschuren LJMJ: Rational development of addiction pharmacotherapies: successes, failures, and prospects. Cold Spring Harb Perspect Med 2012, 2:a012880.

7. Rossi NA, Reid LD: Affective states associated with morphine injections. Physiol Psychol 1976, 4:269-276.

8. Tzschentke TM: Measuring reward with the conditioned place preference (CPP) paradigm: update of the last decade. Addict Biol 2007, 12:227-462.

9. Olds J, Olds ME: Positive reinforcement produced by stimulating hypothalamus with iproniazid and other compounds. Science 1958, 127:1175-1176.

10. Wise RA: Addictive drugs and brain stimulation reward. Annu Rev Neurosci 1996, 19:319-340.

11. Weeks JR: Experimental morphine addiction: method for automatic intravenous injection in unrestrained rats. Science 1962, 138:143-144.

12. O'Connor EC, Chapman K, Butler P, Mead AN: The predictive validity of the rat self-administration model for abuse liability. Neurosci Biobehav Rev 2011, 35:912-938.

13. Hodos W: Progressive ratio as a measure of reward strength. Science 1961, 134:943-944.

14. Richardson NR, Roberts DCS: Progressive ratio schedules in drug self-administration studies in rats: a method to evaluate reinforcing efficacy. J Neurosci Meth 1996, 66:1-11.

15. Goldberg SR: Comparable behavior maintained under fixedratio and second-order schedules of food presentation, cocaine injection or d-amphetamine injection in the squirrel monkey. J Pharmacol Exp Ther 1973, 186:18-30.

16. Everitt BJ, Robbins TW: Second-order schedules of drug reinforcement in rats and monkeys: measurement of reinforcing efficacy and drug-seeking behaviour. Psychopharmacology (Berl) 2000, 153:17-30.

17. De Wit H, Stewart J: Reinstatement of cocaine-reinforced responding in the rat. Psychopharmacology (Berl) 1981, 75:134-143.

18. Bossert JM, Marchant NJ, Calu DJ, Shaham Y: The reinstatement model of drug relapse: recent neurobiological findings, emerging research topics, and translational research. Psychopharmacology (Berl) 2013, 229:453-476.

19. American Psychiatric Association: Diagnostic and Statistical Manual of Mental Disorders. American Psychiatric Association; 2000.

20. American Psychiatric Association: DSM-5 Diagnostic and Statistical Manual of Mental Disorders. 2013.

21. Vanderschuren LJMJ, Ahmed SH: Animals studies of addictive - $\quad$ behavior. Cold Spring Harb Perspect Med 2013, 3:a011932. An overview of animal studies that attempt to model different aspects of addictive behaviour, based on the DSM-IV criteria.

22. Lesscher HMB, Vanderschuren LJMJ: Compulsive drug use and its neural substrates. Rev Neurosci 2012, 23:731-745.

23. Wolffgramm J: An ethopharmacological approach to the development of drug addiction. Neurosci Biobehav Rev 1991, 15:515-519.
24. Wolffgramm J, Heyne A: From controlled drug intake to loss of control: the irreversible development of drug addiction in the rat. Behav Brain Res 1995, 70:77-94.

25. Heyne A, Wolffgramm J: The development of addiction to $d$-amphetamine in an animal model: same principles as for alcohol and opiate. Psychopharmacology (Berl) 1998, 140:510-518.

26. Galli G, Wolffgramm J: Long-term voluntary D-amphetamine consumption and behavioral predictors for subsequent Damphetamine addiction in rats. Drug Alcohol Dep 2004, 73:51-60.

27. Hopf FW, Chang SJ, Sparta DR, Bowers MS, Bonci A: Motivation for alcohol becomes resistant to quinine adulteration after 3-4 months of intermittent alcohol self-administration. Alcohol Clin Exp Res 2010, 34:1565-1573.

28. Seif T, Chang S-J, Simms JA, Gibb SL, Dadgar J, Chen BT,

-. Harvey BK, Ron D, Messing RO, Bonci A et al.: Cortical activation of accumbens hyperpolarization-active NMDARs mediates aversion-resistant alcohol intake. Nat Neurosci 2013, 16:1094-1100.

In this study, the authors demonstrate that aversion-resistant alcohol intake is mediated by a functional change in cortical inputs the to nucleus accumbens core. Importantly, involvement of these cortico-accumbens in alcohol-addiction-like behaviour is shown using two different punishers (i.e., quinine and footshocks), and counteracting their functional changes reduces aversion-resistant alcohol drinking.

29. Lesscher HMB, Van Kerkhof LWM, Vanderschuren LJMJ: Inflexible and indifferent ethanol drinking in mice. Alcohol Clin Exp Res 2010, 34:1219-1225.

30. Spoelder M, Hesseling P, Baars AM, Lozeman-van't Klooster JG, Rotte MD, Vanderschuren LJMJ, Lesscher HMB: Individual variation in alcohol intake predicts reinforcement, motivation, and compulsive alcohol use in rats. Alcohol Clin Exp Res 2015, 39:2427-2437.

31. Lesscher HMB, Houthuijzen JM, Groot Koerkamp M,

- Holstege FCP, Vanderschuren LJMJ: Amygdala 14-3-3æ as a novel modulator of escalating alcohol intake in mice. PLOS ONE 2012, 7:e37999.

Using a gene expression screen, this study reveals that increased expression of the adapter protein 14-3-3 $\zeta$ in the amygdala during initia alcohol intake may protect against escalation of alcohol drinking, and resistance to punishment.

32. Loi B, Lobina C, Maccioni P, Fantini N, Carai MA, Gessa GL, Colombo G: Increase in alcohol intake, reduced flexibility of alcohol drinking, and evidence of signs of alcohol intoxication in Sardinian alcohol-preferring rats exposed to intermittent access to $20 \%$ alcohol. Alcohol Clin Exp Res 2010 , 34:2147-2154.

33. Fachin-Scheit DJ, Frozino Ribeiro A, Pigatto G, Oliveira Goeldner F, Boerngen de Lacerda R: Development of a mouse model of ethanol addiction: naltrexone efficacy in reducing consumption but not craving. J Neural Transm 2006, 113:1305-1321.

34. Dickinson A: Actions and habits: the development of behavioural autonomy. Phil Trans R Soc Lond B 1985, 308:67-78.

35. Dickinson A, Wood N, Smith JW: Alcohol seeking by rats: action or habit? Q J Exp Psychol 2002, 55B:331-348.

36. Miles FJ, Everitt BJ, Dickinson A: Oral cocaine seeking by rats: action or habit? Behav Neurosci 2003, 117:927-938.

37. Leong K-C, Berini CR, Ghee SM, Reichel CM: Extended

- cocaine-seeking produces a shift from goal-directed to habitual responding in rats. Physiol Behav 2016, 164:330-335.

This study is the first to use lithium chloride as a punisher of intravenous cocaine self-administration. Importantly, the authors report that cueinduced cocaine seeking is less sensitive to lithium chloride punishment than cocaine taking.

38. Holtz NA, Carroll ME: Cocaine self-administration punished by intravenous histamine in adolescent and adult rats. Behav Pharmacol 2015, 26:393-397. 
39. Negus SS: Effects of punishment on choice between cocaine and food in rhesus monkeys. Psychopharmacology (Berl) 2005 181:244-252.

40. Woolverton WL, Freeman KB, Myerson J, Green L: Suppression of cocaine self-administration in monkeys: effects of delayed punishment. Psychopharmacology (Berl) 2012, 220:509-517.

41. Jenkins TN, Warner LH, Warden CJ: Standard apparatus for the study of animal motivation. J Comp Psychol 1926, 6:361-382.

42. Bergman J, Johanson CE: The effects of electric shock on responding maintained by cocaine in rhesus monkeys. Pharmacol Biochem Behav 1981, 14:423-426.

43. Grove RN, Schuster CR: Suppression of cocaine selfadministration by extinction and punishment. Pharmacol Biochem Behav 1974, 2:199-208.

44. Panlilio LV, Thorndike EB, Schindler CW: Reinstatement of punishment-suppressed opioid self-administration in rats: an alternative model of relapse to drug abuse. Psychopharmacology (Berl) 2003, 168:229-235.

45. Deroche-Gamonet V, Belin D, Piazza PV: Evidence for addictionlike behavior in the rat. Science 2004, 305:1014-1017.

46. Belin D, Balado E, Piazza PV, Deroche-Gamonet V: Pattern of intake and drug craving predict the development of cocaine addiction-like behavior in rats. Biol Psychiatry 2009, 65:863-868.

47. Belin D, Berson N, Balado E, Piazza PV, Deroche-Gamonet V: High-novelty-preference rats are predisposed to compulsive cocaine self-administration. Neuropsychopharmacology 2011, 36:569-579.

48. Belin D, Mar AC, Dalley JW, Robbins TW, Everitt BJ: High impulsivity predicts the switch to compulsive cocaine-taking Science 2008, 320:1352-1355.

49. Pelloux $Y$, Everitt BJ, Dickinson A: Compulsive drug seeking by rats under punishment: effects of drug taking history. Psychopharmacology (Berl) 2007, 194:127-137.

50. Jonkman S, Pelloux Y, Everitt BJ: Drug intake is sufficient, but conditioning is not necessary for the emergence of compulsive cocaine seeking after extended selfadministration. Neuropsychopharmacology 2012, 37:1612-1619.

51. Pelloux Y, Murray JE, Everitt BJ: Differential vulnerability to the

- punishment of cocaine related behaviours: effects of locus of punishment, cocaine taking history and alternative reinforcer availability. Psychopharmacology (Berl) 2015, 232:125-134.

This study compares punishment of cocaine seeking and cocaine taking, and whether access to an alternative reinforcer changes the sensitivity of cocaine self-administration to punishment. As such, it provides important information about the structure of addictive behaviour, and how behavioural interventions can be effective treatments for addiction.

52. Xue Y, Steketee JD, Sun W: Inactivation of the central nucleus of the amygdala reduces the effect of punishment on cocaine self-administration in rats. Eur J Neurosci 2012, 35:775-783.

53. Chen BT, Yau H-J, Hatch C, Kusumoto-Yoshida I, Cho SL,

-• Hopf FW, Bonci A: Rescuing cocaine-induced prefrontal cortex hypoactivity prevents compulsive cocaine seeking. Nature 2013, 496:359-362.

This study shows that individual differences in the sensitivity to punishment of cocaine self-administration can be traced back to altered function of the prelimbic prefrontal cortex. Importantly, using optogenetics, the authors show that there is a bidirectional relationship between prelimbic function and punishment sensitivity of cocaine self-administration.

54. Limpens JHW, Schut EHS, Voorn P, Vanderschuren LJMJ: Using conditioned suppression to investigate compulsive drug seeking in rats. Drug Alcohol Depend 2014, 142:314-324.

55. Kearns DN, Weiss SJ, Panlilio LV: Conditioned suppression of behavior maintained by cocaine self-administration. Drug Alcohol Dep 2002, 65:253-261.

56. Vanderschuren LJMJ, Everitt BJ: Drug seeking becomes compulsive after prolonged cocaine self-administration. Science 2004, 305:1017-1019.
57. Teegarden SL, Bale TL: Decreases in dietary preference produce increased emotionality and risk for dietary relapse. Biol Psychiatry 2007, 61:1021-1029.

58. Cottone P, Wang X, Park JW, Valenza M, Blasio A, Kwak J, lyer MR, Steardo L, Rice KC, Hayashi T et al.: Antagonism of sigma-1 receptors blocks compulsive-like eating. Neuropsychopharmacology 2012, 37:2593-2604.

59. Barnea-Ygael N, Yadid G, Yaka R, Ben-Shahar O, Zangen A: Cueinduced reinstatement of cocaine seeking in the rat "conflict model": effect of prolonged home-cage confinement. Psychopharmacology (Berl) 2012, 219:875-883.

60. Cooper A, Barnea-Ygael N, Levy D, Shaham Y, Zangen A: A conflict rat model of cue-induced relapse to cocaine seeking. Psychopharmacology (Berl) 2007, 194:117-125.

61. Peck JA, Wercberger R, Kariyeva E, Ranaldi R: Cue-induced resumption of heroin and cocaine seeking in rats using a conflict model of abstinence and relapse. Psychopharmacology (Berl) 2013, 228:651-658.

62. Saunders BT, Yager LM, Robinson TE: Cue-evoked cocaine "craving": role of dopamine in the accumbens core. J Neurosci 2013, 33:13989-14000.

63. Marchant NJ, Khuc TN, Pickens CL, Bonci A, Shaham Y: Contextinduced relapse to alcohol seeking after punishment in a rat model. Biol Psychiatry 2013, 73:256-262.

64. Krasnova IN, Marchant NJ, Ladenheim B, McCoy MT, Panlilio LV, Bossert JM, Shaham Y, Cadet JL: Incubation of methamphetamine and palatable food craving after punishment-induced abstinence. Neuropsychopharmacology 2014, 30:2008-2016.

65. Kasanetz F, Deroche-Gamonet V, Berson N, Balado E, Lafourcade M, Manzoni O, Piazza PV: Transition to addiction is associated with a persistent impairment in synaptic plasticity Science 2010, 328:1709-1712.

66. Kasanetz F, Lafourcade M, Deroche-Gamonet V, Revest JM, Berson N, Balado E, Fiancette JF, Renault P, Piazza PV, Manzoni OJ: Prefrontal synaptic markers of cocaine addictionlike behavior in rats. Mol Psychiatry 2013, 18:729-737.

67. Jonkman S, Pelloux Y, Everitt BJ: Differential roles of the dorsolateral and midlateral striatum in punished cocaine seeking. J Neurosci 2012, 32:4645-4650.

68. Pelloux Y, Dilleen R, Economidou D, Theobald D, Everitt BJ: Reduced forebrain serotonin transmission is causally involved in the development of compulsive cocaine seeking in rats. Neuropsychopharmacology 2012, 37:2505-2514.

69. Pelloux Y, Murray JE, Everitt BJ: Differential roles of the prefrontal cortical subregions and basolateral amygdala in compulsive cocaine seeking and relapse after voluntary abstinence in rats. Eur J Neurosci 2013, 38:3018-3026.

70. Limpens JHW, Damsteegt R, Broekhoven MH, Voorn P, Vanderschuren LJMJ: Inactivation of the prelimbic cortex emulates compulsive reward seeking in rats. Brain Res 2015 1628:210-218

71. Seif T, Simms JA, Lei K, Wegner S, Bonci A, Messing RO, Hopf FW: $\mathrm{D}$-serine and $\mathrm{D}$-cycloserine reduce compulsive alcohol intake in rats. Neuropsychopharmacology 2015, 40:2357-2367.

72. Leon DA, Saburova L, Tomkins S, Andreev E, Kiryanov N, McKee M, Shkolnikov VM: Hazardous alcohol drinking and premature mortality in Russia: a population based casecontrol study. Lancet 2007, 369:2001-2009.

73. Soo Hoo GW, Hinds RL, Dinovo E, Renner SW: Fatal largevolume mouthwash ingestion in an adult: a review and the possible role of phenolic compound toxicity. $J$ Intensive Care Med 2003, 18:150-155.

74. Dickinson A, Watt A, Griffiths WJH: Free-operant acquisition with delayed reinforcement. Q J Exp Psychol 1992, 45B:241-258.

75. Ersche KD, Gillan CM, Jones PS, Williams GB, Ward LH, Luijten M,

-. de Wit S, Sahakian BJ, Bullmore ET, Robbins TW: Carrots and sticks fail to change behavior in cocaine addiction. Science 2016, 352:1468-1471. 
In this important experiment, the authors demonstrate that cocaine addicted humans are less sensitive to punishment of electric shock in an active avoidance task. As such, it provides important translational support for punishment approaches to study addictive behaviour.

76. Baarendse PJJ, Limpens JHW, Vanderschuren LJMJ: Disrupted social development enhances the motivation for cocaine. Psychopharmacology (Berl) 2014, 231:1695-1704.

77. Lesscher HMB, Spoelder M, Rotte MD, Janssen MJ, Hesseling P, Lozeman-van't Klooster JG, Baars AM, Vanderschuren LJMJ: Early social isolation augments alcohol consumption in rats. Behav Pharmacol 2015, 26:673-680.

78. Lenoir M, Serre F, Cantin L, Ahmed SH: Intense sweetness surpasses cocaine reward. PLOS ONE 2007, 2:e698.

79. Lenoir M, Cantin L, Vanhille N, Serre F, Ahmed SH: Extended heroin access increases heroin choices over a potent nondrug alternative. Neuropsychopharmacology 2013, 38:1209-1220.

80. Shaham Y, Shalev U, Lu L, De Wit H, Stewart J: The reinstatement model of drug relapse: history, methodology and major findings. Psychopharmacology (Berl) 2003, 168:3-20.

81. Heilig M, Epstein DH, Nader MA, Shaham Y: Time to connect:

- bringing social context into addiction neuroscience. Nat Rev Neurosci 2016, 17:592-599.

An important call to incorporate social factors into addiction research.
82. Morgan D, Grant KA, Gage HD, Mach RH, Kaplan JR, Prioleau O Nader SH, Buchheimer N, Ehrenkaufer RL, Nader MA: Social dominance in monkeys: dopamine $D_{2}$ receptors and cocaine self-administration. Nat Neurosci 2002, 5:169-174.

83. Trezza V, Baarendse PJJ, Vanderschuren LJMJ: On the interaction between drugs of abuse and adolescent social behavior. Psychopharmacology (Berl) 2014, 231:1715-1729.

84. Radke AK, Nakazawa K, Holmes A: Cortical GluN2B deletion attenuates punished suppression of food seeking. Psychopharmacology (Berl) 2015, 232:3753-3761.

85. Radke AK, Jury NJ, Kocharian A, Marcinkiewcz CA, Lowery-Gionta EG, Pleil KE, McElligot ZA, McKlveen JM, Kash TL Holmes A: Chronic EtOH effects on putative measures of compulsive behavior in mice. Addict Biol 2015 http://dx.doi.org/ 10.1111/adb.12342.

86. De Jong JW, Roelofs TJM, Mol FMU, Hillen AEJ, Meijboom KTE, Luijendijk MCM, van der Eerden HAM, Garner KM, Vanderschuren LJMJ, Adan RAH: Reducing ventral tegmental dopamine D2 receptor expression selectively boosts incentive motivation. Neuropsychopharmacology 2015 , 40:2085-2095 